\title{
Repetitive Saliva Swallowing Test Predicts COPD Exacerbation
}

This article was published in the following Dove Press journal:

International Journal of Chronic Obstructive Pulmonary Disease

\author{
Yuki Yoshimatsu (D) \\ Kazunori Tobino ${ }^{1,2}$ \\ Takuto Sueyasu' \\ Saori Nishizawa' \\ Yuki Ko' \\ Mina Yasuda' \\ Hiromi Ide' \\ Kosuke Tsuruno' \\ Hiroyuki Miyajima'
}

'Department of Respiratory Medicine, lizuka Hospital, Fukuoka 820-8505, Japan;

${ }^{2}$ Department of Respiratory Medicine, Juntendo University Graduate School of Medicine, Tokyo II3-843I, Japan
Correspondence: Yuki Yoshimatsu Department of Respiratory Medicine, lizuka Hospital, 3-83 Yoshio lizuka, Fukuoka 820-8505, Japan

Tel +8I 948223800

$\mathrm{Fax}+81948295744$

Email yukitsukihana0105@gmail.com
Introduction: Predicting phenotypes at risk of chronic obstructive pulmonary disease (COPD) exacerbation is extremely important. Dysphagia is becoming recognized as one of these phenotypes. A convenient method of screening for dysphagia and COPD exacerbation risk is desired. The repetitive saliva swallowing test (RSST) is one of the least invasive dysphagia screening methods. We previously reported the possible relation between the RSST result and COPD exacerbation in a retrospective study. Based on this, we performed a prospective study to evaluate the efficacy of RSST as a predictor of COPD exacerbation and to determine its optimal cut-off value for COPD.

Methods: Seventy patients with COPD were recruited. Patients underwent the following dysphagia screening tests: the 10-item Eating Assessment Tool, Frequency Scale for the Symptoms of Gastroesophageal Reflux Disease, RSST, water swallowing test, and simple swallow provocation test. After one year, they were classified into two groups according to the presence of COPD exacerbation during the follow-up period.

Results: Twenty-seven patients had one or more exacerbations in the past year. During the follow-up period, 28 patients had one or more exacerbations (E group), and 42 had none (non-E group). There were no significant differences between the groups except for the presence of past exacerbations and the results of the RSST, when the cut-off value was set at 2, 3, 4, or 5 swallows. The number of swallows in the RSST was significantly lower in the E group than in the Non-E group. A cut-off value of 5 was the most effective. The time to first exacerbation was significantly longer in those with an RSST value of $>5$. The RSST was more reliable for differentiating the E group and non-E group than the presence of exacerbation in the past year (hazard ratios: 13.78 and 2.70, respectively).

Conclusion: An RSST cut-off value of 5 may be a strong predictor of COPD exacerbation. Keywords: dysphagia, screening, aspiration, phenotype, risk

\section{Introduction}

Cases of chronic obstructive pulmonary disease (COPD) are increasing, as is the social impact of this disease. Its morbidity is largely dependent on COPD exacerbation. Therefore, efforts to identify patients at particular risk of exacerbation are more important than ever. ${ }^{1}$

Dysphagia is becoming recognized as a risky phenotype. Patients with COPD become complicated with dysphagia in an early stage, and this potentially leads to pneumonia, malnutrition, and COPD exacerbation. ${ }^{2}$ The simple swallow provocation test (SSPT) has been reported to be able to predict COPD exacerbation; however, this test is not as simple to perform as it sounds for either physicians or 
patients. $^{3,4}$ A more convenient method of screening for dysphagia and COPD exacerbation risk is therefore desired.

Among the numerous dysphagia screening tests available, the repetitive saliva swallowing test (RSST) may be one of the least invasive methods. We previously reported the possible relationship between the RSST result and COPD exacerbation in a retrospective study, in which COPD patients with exacerbation in the past year scored lower on the RSST than those without exacerbation. ${ }^{5}$ However, the cause-and-effect relationship between the RSST and COPD exacerbation was not clear (i.e. the decline in the RSST result may have been the cause of the COPD exacerbation or the result of it). Furthermore, as the RSST was initially developed for functional dysphagia patients (in whom dysphagia is often apparent), the cut-off value of the RSST for COPD exacerbation (where dysphagia is typically unnoticed) was unclear.

Therefore, we performed a prospective study to evaluate the efficacy of the RSST as a predictor of COPD exacerbation and searched for an optimal cut-off value of the RSST for COPD exacerbation.

\section{Methods}

\section{Patients}

This study was part of a prospective study of COPD patients from the Iizuka COPD cohort. Ethical approval was provided by the Iizuka Hospital Ethics Committee as instituted by the Declaration of Helsinki (Number 17,026), and written informed consent was obtained from all patients.

Seventy patients with COPD were recruited from the outpatient clinic of Iizuka Hospital Department of Respiratory Medicine from March 28 to September 22, 2017. COPD was diagnosed according to the GOLD 2017 criteria. ${ }^{6}$ Patients with bronchial asthma or asthmaCOPD overlap were excluded. Patients were also excluded if they had other medical conditions that might cause dysphagia (neurologic diseases, head and neck cancer, achalasia, scleroderma, and esophageal cancer), chronic respiratory failure (interstitial pneumonia, unstable heart failure or pneumoconiosis), or a poor general condition (Eastern Cooperative Oncology Group Performance Status Scale 3-4, active malignancy or dementia).

Information was extracted from medical records regarding demography, the body mass index (BMI), and the lung function determined within three months of inclusion. The history of moderate to severe COPD exacerbation in the past year was assessed from medical records and patient recollection. COPD exacerbation was defined by the presence of new or worsening COPD symptoms (cough, sputum, wheezing, dyspnea, or chest tightness), at least one of which lasted for three days or more. Furthermore, exacerbation was defined as moderate or severe when requiring one of the following: systemic steroid administration, antibiotic therapy, or hospital admission. ${ }^{7,8}$ Upon inclusion, patients underwent the dysphagia screening tests described below.

\section{Dysphagia Screening Tests}

Dysphagia screening in our clinic is performed using the 10item Eating Assessment Tool (EAT-10), ${ }^{9,10}$ Frequency Scale for the Symptoms of Gastroesophageal Reflux Disease (FSSG), ${ }^{11}$ RSST, $^{12}$ water swallowing test (WST), ${ }^{13}$ and SSPT. These screening tests were carried out during the same visit and in a stable state, defined as more than four weeks of a stable respiratory condition without COPD exacerbation.

\section{EAT-I0}

This self-administered and easy-scored questionnaire consists of 10 questions concerning the patient's symptoms related to swallowing in order to assess the dysphagia symptom severity. An EAT-10 score of $>3$ is abnormal and indicates the presence of swallowing difficulties.

\section{FSSG}

This scale was developed to evaluate the severity and therapeutic response of gastroesophageal reflux disease (GERD). It is used routinely in COPD patients to screen for GERD. An FSSG score of $\geq 8$ indicates a high possibility of GERD.

\section{RSST}

The RSST is intended to safely screen the patient's ability to swallow repeatedly. Patients are told to swallow as many times as possible in 30 seconds. Two or fewer dry swallows within 30 seconds are considered abnormal.

\section{WST}

This test is intended to detect aspiration with high accuracy. Two methods with either $3 \mathrm{~mL}$ or $30 \mathrm{~mL}$ of water are commonly used in Japan. In our clinic, we use the $30-\mathrm{mL}$ method in order to detect aspiration in COPD patients who are otherwise generally well. Patients are asked to drink a cup containing $30 \mathrm{~mL}$ of water in their usual manner. 
Their drinking pattern and vocal change (wet voice) after drinking are recorded. Drinking patterns are defined as follows: 1, drinks $30 \mathrm{~mL}$ in 1 swallow without choking; 2, drinks $30 \mathrm{~mL}$ in multiple swallows without choking; 3, drinks $30 \mathrm{~mL}$ in one swallow with some choking; 4, drinks $30 \mathrm{~mL}$ in multiple swallows with some choking; 5, chokes and has difficulty drinking $30 \mathrm{~mL}$.

\section{SSPT}

This is considered a standard screening method for dysphagia. It can be used to screen for silent aspiration too. A thin tube is inserted through the nose into the oropharynx area, and small volumes of water $(0.4$ and $2.0 \mathrm{~mL})$ are injected. The time from injection to the initiation of the swallowing reflex is measured, and $\geq 3$ seconds is considered abnormal. $^{3,4}$

The patients were given a diary to record their daily symptoms and medications taken. They were followed up for one year. After one year, the patients were classified into two groups according to the presence of COPD exacerbation during the follow-up period (exacerbation group, E group; and non-exacerbation group, Non-E group). Patients background characteristics and the results of the dysphagia screening tests were then compared between the groups.

\section{Statistical Analyses}

Descriptive statistics for baseline data were presented as the percentage, mean, and standard deviation. Differences between the two groups were examined using MannWhitney's $U$-test and Fischer's exact test. A p-value of $<0.05$ was considered to indicate a statistically significant difference. When there was a statistically significant difference between the two groups in any of the dysphagia screening results, a receiver operating characteristic (ROC) curve analysis was performed in order to evaluate its utility in the differentiation of the two groups. A Log-rank analysis and univariate Cox regression analysis were performed to identify the best predictors of COPD exacerbation. All data analyses were carried out using the JMP Pro software program (ver. 14; SAS Institute, Cary, $\mathrm{NC}$, USA).

\section{Results}

Patients' background data are shown in Table 1. There were 59 males $(84.3 \%)$ and 11 females $(15.7 \%)$. The mean age was $72.8 \pm 7.5$ years old, and the mean BMI was $21.7 \pm 3.9 \mathrm{~kg} / \mathrm{m}^{2}$. Severities of air-flow obstruction
Table I Patient Characteristics

\begin{tabular}{|c|c|c|c|c|}
\hline & $\begin{array}{l}\text { Total } \\
\mathbf{N}=70\end{array}$ & $\begin{array}{l}\text { E Group } \\
N=28\end{array}$ & $\begin{array}{l}\text { Non-E } \\
\text { Group } \\
N=42\end{array}$ & $p$ value \\
\hline Age (years old) & $72.8 \pm 7.5$ & $73.9 \pm 8.0$ & $72.1 \pm 7.2$ & 0.34 \\
\hline Male/Female & $59 / 11$ & $22 / 6$ & $37 / 5$ & 0.33 \\
\hline BMI $\left(\mathrm{kg} / \mathrm{m}^{2}\right)$ & $21.7 \pm 3.9$ & $20.8 \pm 4.4$ & $22.3 \pm 3.4$ & 0.11 \\
\hline $\begin{array}{l}\text { GOLD Stage } \\
\text { I } \\
\text { II } \\
\text { III } \\
\text { IV }\end{array}$ & $\begin{array}{l}15(21.4) \\
25(35.7) \\
21(30.0) \\
9(12.9)\end{array}$ & $\begin{array}{l}4(14.3) \\
7(25.0) \\
11(39.3) \\
6(21.4)\end{array}$ & $\begin{array}{l}\text { II (26.2) } \\
18(42.9) \\
10(23.8) \\
3(7.1)\end{array}$ & 0.24 \\
\hline $\begin{array}{l}\text { History of } \\
\text { exacerbations in } \\
\text { the past year }\end{array}$ & $27(38.6)$ & $16(57.1)$ & II (26.2) & 0.01 \\
\hline
\end{tabular}

Note: Data in parentheses are percentages.

Abbreviations: E group, exacerbation group; Non-E group, non-exacerbation group.

based on GOLD staging in our patients were as follows: I, 15 (21.4\%); II, 25 (35.7\%); III, 21 (30.0\%); and IV, 9 $(12.9 \%)$. Twenty-seven (38.6\%) had experienced one or more moderate to severe exacerbations in the past year, and $43(61.4 \%)$ had experienced none. During the 1-year follow-up period, 28 patients $(40.0 \%)$ had experienced one or more exacerbations (E group), and 42 (60\%) had experienced no exacerbations (Non-E group). There were no significant differences in the patient background characteristics between the two groups except for in the presence of past exacerbations. Patients in the E group were significantly more likely to have experienced one or more episodes of exacerbations in the previous year than those in the Non-E group.

Dysphagia screening results are shown in Table 2 . There was no significant difference between the two groups in the results of the EAT-10, FSSG, WST, and SSPT. Statistically significant differences between the groups were observed in the results of RSST when the cut-off value was set at 2, 3, 4, or 5 swallows per 30 seconds $(\mathrm{p}<0.01)$. The difference between the groups in the results of the RSST was not statistically significant at cut-off values of 1 or $\geq 6$. The number of swallows per 30 seconds in the RSST was significantly lower in the $\mathrm{E}$ group than in the Non-E group (3.3 \pm 1.4 vs. $5.0 \pm 1.6$ times, $\mathrm{p}<0.01)$.

Figure 1 shows the ROC curve analysis using the swallowing frequency in the RSST to differentiate the two groups. With an RSST swallowing frequency of $\leq 5$ 
Table 2 The Comparison of the Dysphagia Screening Results Between the Two Groups

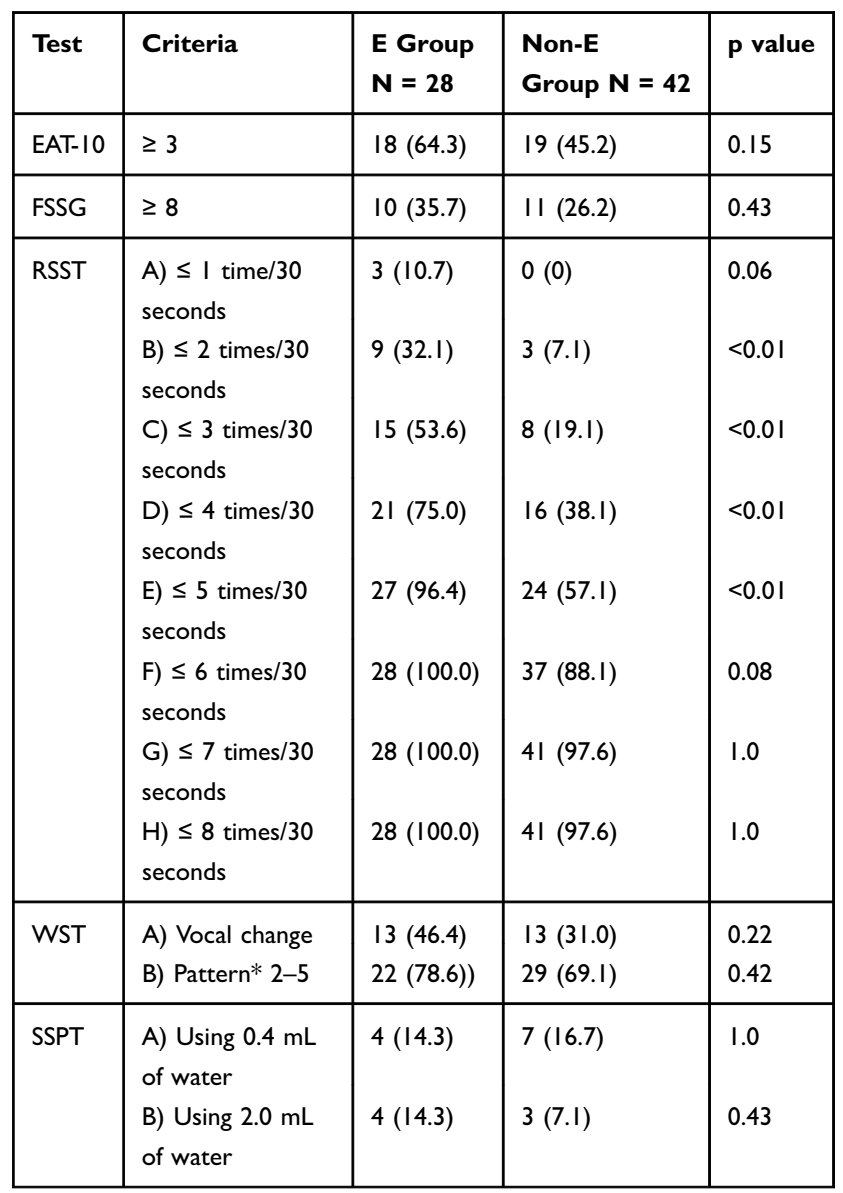

Notes: *Drinking patterns are defined as follows: I, drinks $30 \mathrm{~mL}$ in I swallow without choking; 2, drinks $30 \mathrm{~mL}$ in multiple swallows without choking; 3, drinks $30 \mathrm{~mL}$ in one swallow with some choking; 4, drinks $30 \mathrm{~mL}$ in multiple swallows with some choking; 5, chokes and has difficulty drinking $30 \mathrm{~mL}$. Data in parentheses are percentages.

Abbreviations: E group, exacerbation group; Non-E group, non-exacerbation group; FSSG, frequency scale for the symptoms of gastroesophageal reflux disease; RSST, repetitive saliva swallowing test; WST, water swallowing test; SSPT, simple swallowing provocation test.

times considered abnormal, the sensitivity and specificity were $42.9 \%$ and $96.4 \%$, respectively, and the area under the ROC curve was 0.775 (95\% confidence interval [CI], 0.670-0.881). The correlation coefficient of the number of swallows in the RSST and the number of exacerbations during follow-up was negative $(-0.465)$. In other words, the fewer the number of swallows in the RSST, the greater the risk of exacerbation during the follow-up.

In Figure 2, Kaplan-Meier curves with the log rank test and univariate Cox regression analysis were used to compare the time to first COPD exacerbation of all severities. The time to first exacerbation was significantly longer in patients with a history of exacerbation in the past year than in those with no such history

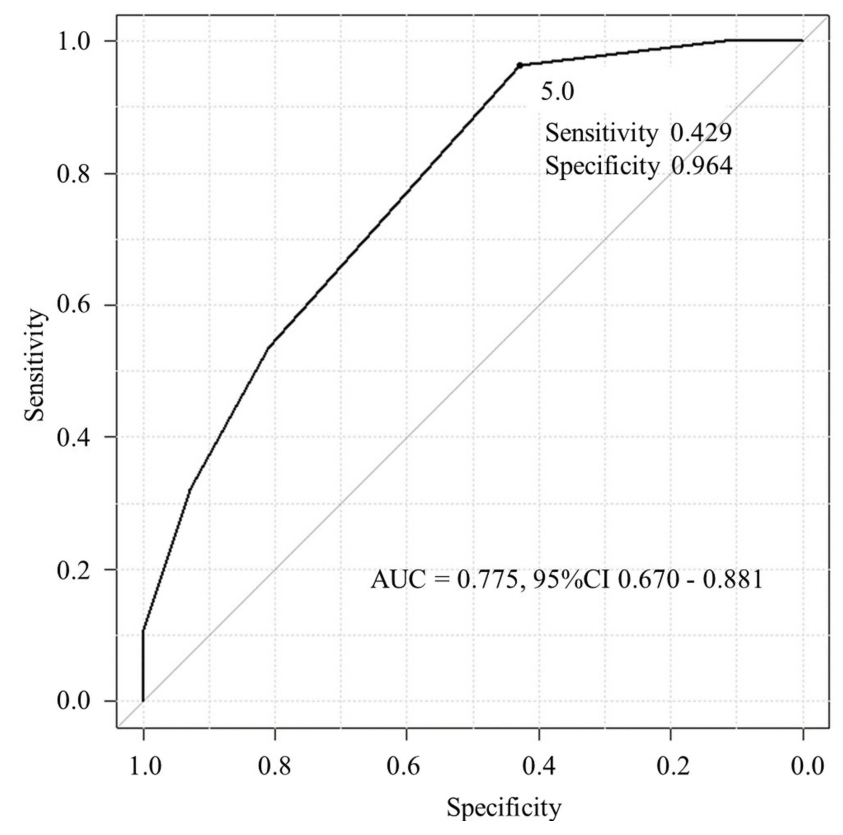

Figure I Results of an ROC curve analysis using the swallow frequency in RSST. When the RSST cut-off value was set at 5.0 , the sensitivity and specificity were 0.429 and 0.964 , respectively, and the area under the ROC curve was 0.775 .

(median not applicable (NA) vs. 301 days, $\mathrm{p}=0.007$ ) and in those with an RSST value of $>5$ than in those with lower values (median NA vs. 350 days, $p=0.001$ ). The RSST was thought to be more reliable for differentiating the E group and non-E group than the presence of exacerbation in the past year (hazard ratio: 13.78 and 2.70, respectively). Furthermore, this difference was more pronounced when the time to first moderate or severe exacerbation was set as an event (Figure 3).

Table 3 shows the relationship between the history of exacerbations in the past year and the results of the RSST using a cut-off value of 5 . There was a statistically significant relationship between both parameters $(p=0.005$, Fischer's exact test).

No significant relationship was detected between the \%FEV1 and the number of swallows in the RSST. The Spearman's rank correalation coefficient was 0.149 $(\mathrm{p}=0.218 ;$ Figure 4$)$.

\section{Discussion}

We conducted a prospective study of COPD patients in order to determine the optimal cut-off value of the RSST to identify the phenotype at a particular risk of exacerbation. Our results showed that patients who had fewer swallows in the RSST had a higher risk of exacerbation in the following year. An RSST cut-off value of "5 times 
A

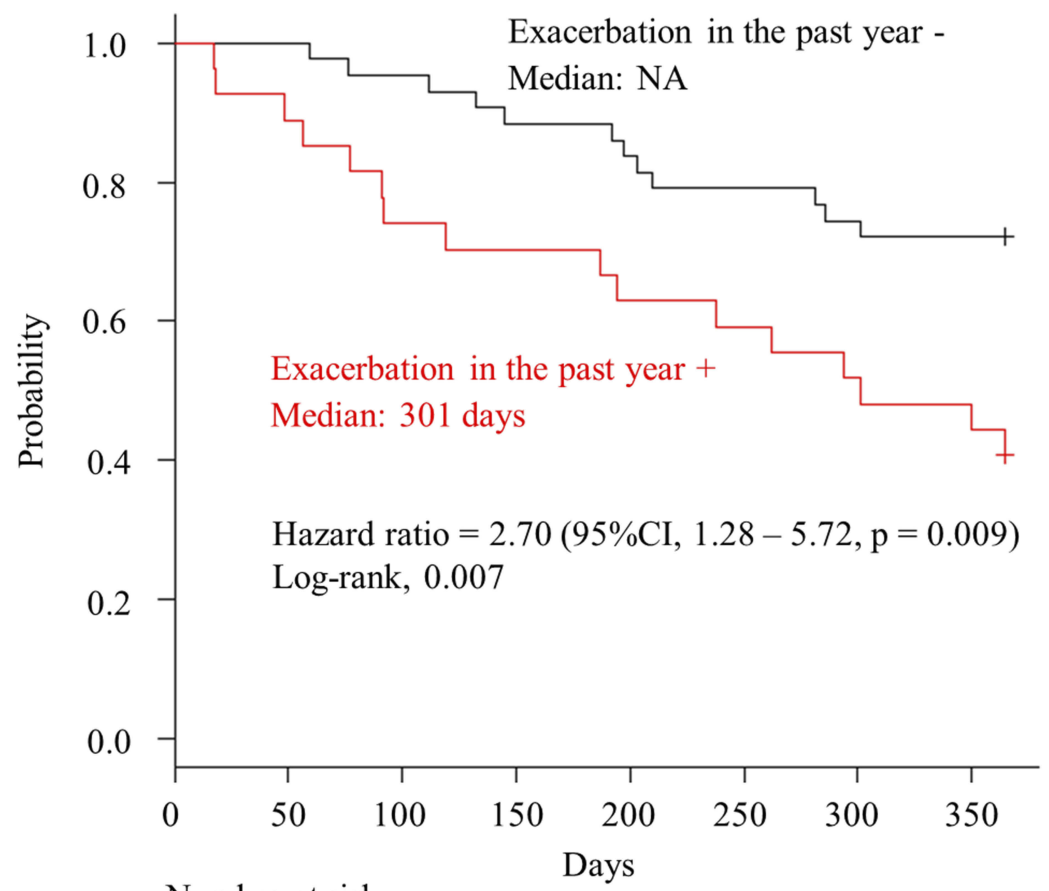

Number at risk

$\begin{array}{lllllllll}\text { Exacerbation in the past year - } & 43 & 43 & 41 & 38 & 36 & 34 & 32 & 31 \\ \text { Exacerbation in the past year }+ & 27 & 24 & 20 & 19 & 17 & 16 & 14 & 13\end{array}$

B

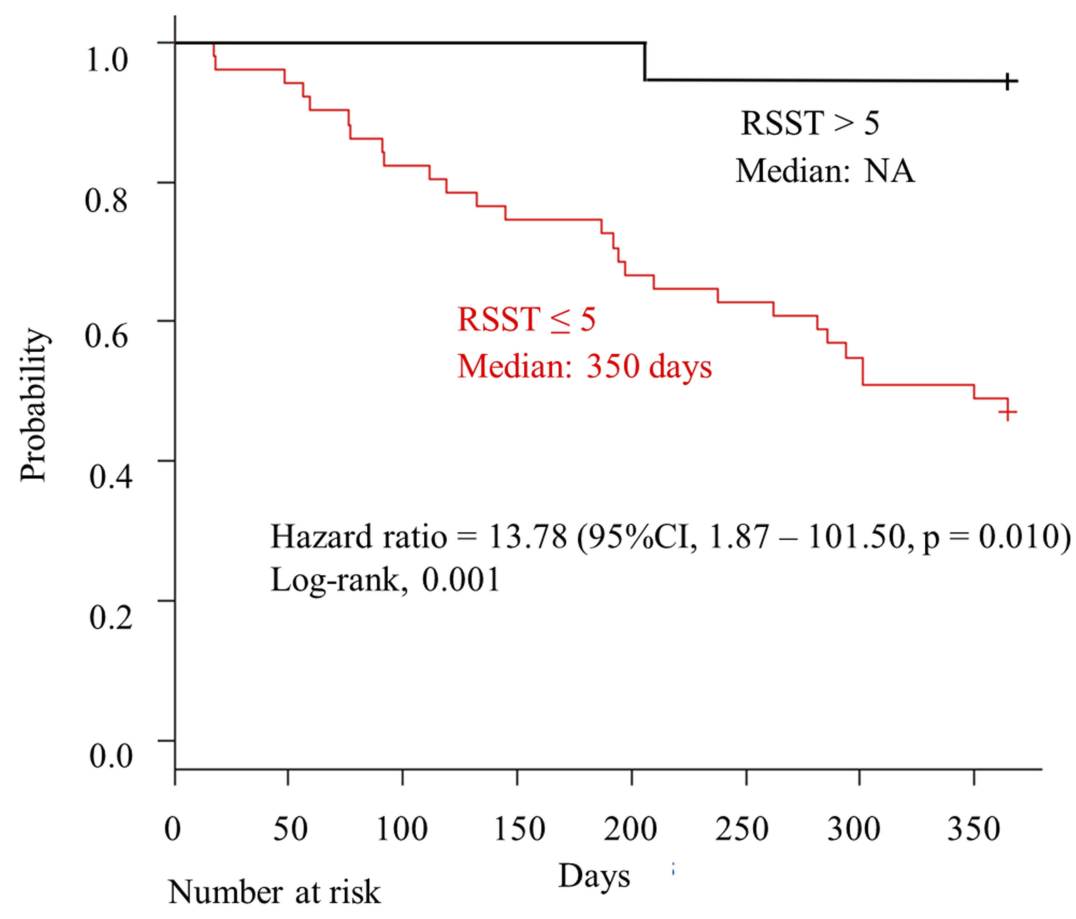

$\begin{array}{lllllllll}\text { RSST }>5 & 19 & 19 & 19 & 19 & 19 & 18 & 18 & 18 \\ \text { RSST } \leq 5 & 51 & 48 & 42 & 38 & 34 & 32 & 28 & 26\end{array}$

Figure 2 Kaplan-Meier curves of the time to first exacerbation (any severity) (A) stratified by the presence of exacerbation in the past year and (B) stratified by the RSST cut-off value of 5 . The time to first exacerbation was significantly longer in patients with a history of exacerbation in the past year than in those with no such history (A) and in those with an RSST value of $>5$ (B). The RSST was a stronger predictor of exacerbation than a history of exacerbation. 
A

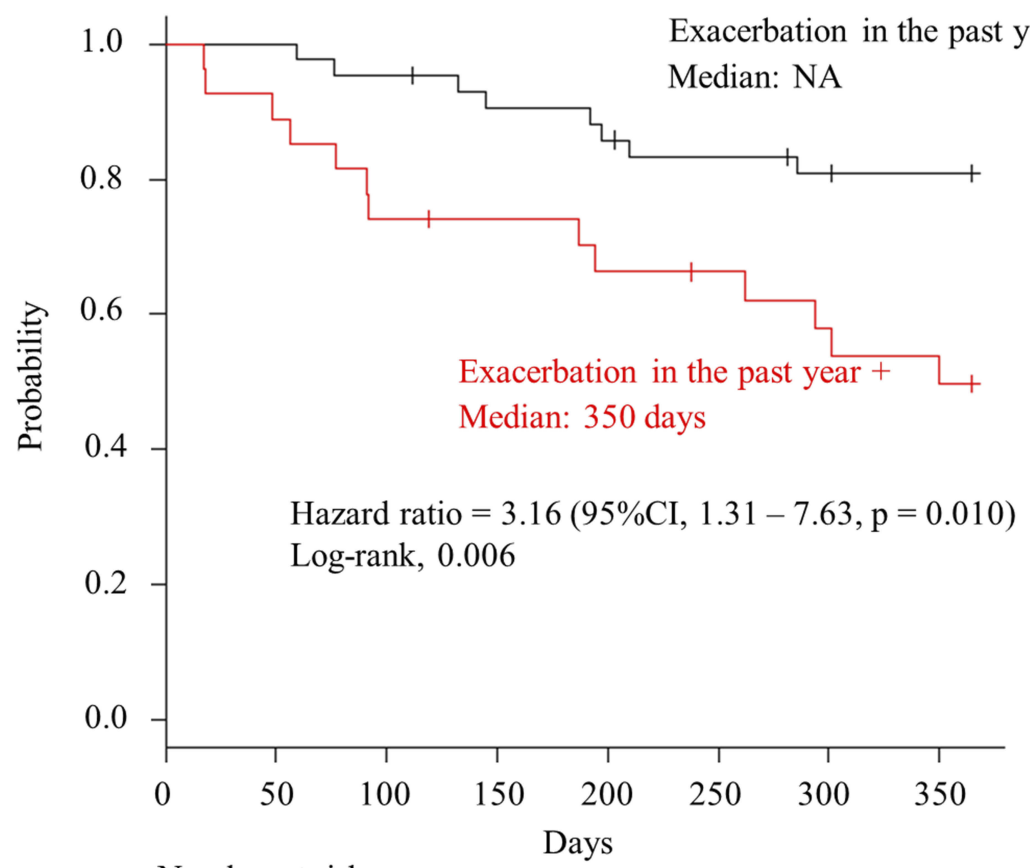

Number at risk

$\begin{array}{lllllllll}\text { Exacerbation in the past year - } & 43 & 43 & 41 & 38 & 36 & 34 & 32 & 31 \\ \text { Exacerbation in the past year }+ & 27 & 24 & 20 & 19 & 17 & 16 & 14 & 13\end{array}$

B

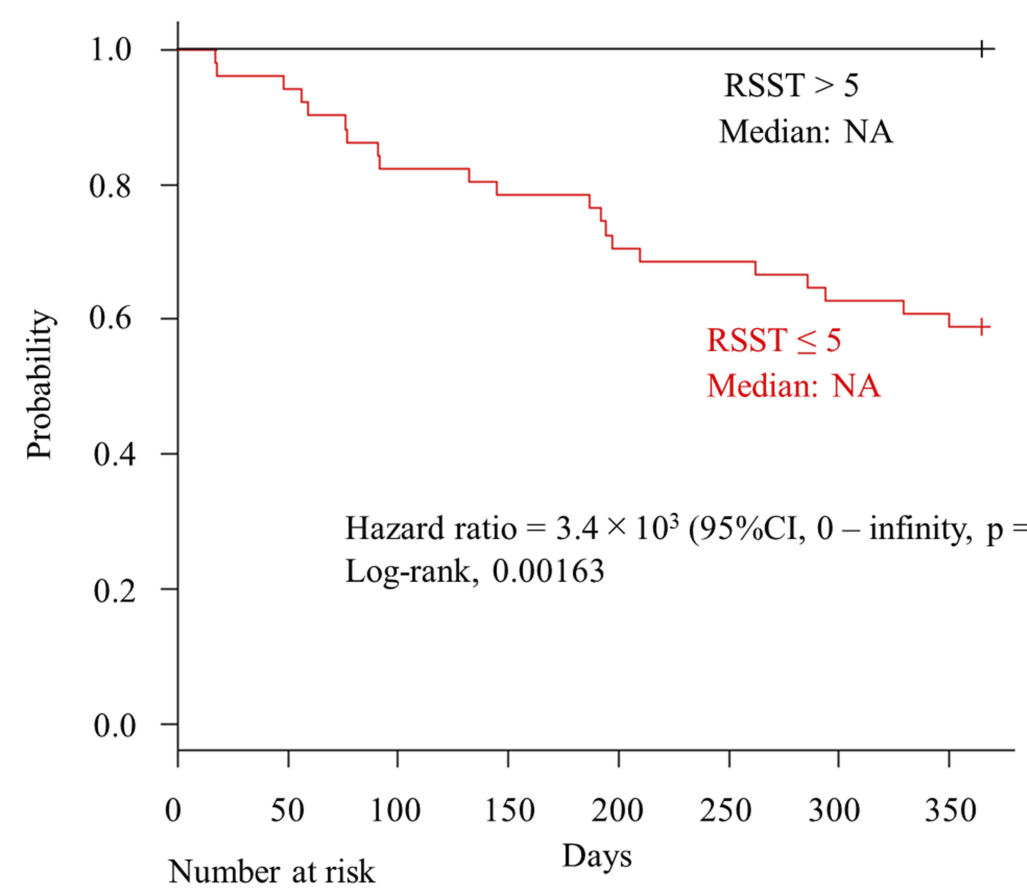

$\begin{array}{lllllllll}\text { RSST }>5 & 19 & 19 & 19 & 19 & 19 & 19 & 19 & 19 \\ \text { RSST } \leq 5 & 51 & 48 & 42 & 40 & 36 & 35 & 32 & 31\end{array}$

Figure 3 Kaplan-Meier curves of the time to first moderate or severe exacerbation (A) stratified by the presence of exacerbation in the past year and (B) stratified by the RSST cut-off value of 5 . The time to first moderate or severe exacerbation was significantly longer in patients with a history of exacerbation in the past year than in those with no such history $(\mathbf{A})$ and in those with an RSST value of $>5$ (B). The RSST was a stronger predictor of exacerbation than a history of exacerbation. This difference was more pronounced when the time to first moderate or severe exacerbation was set as an event. 
Table 3 The Relationship Between a History of Exacerbation in the Past Year and the Results of the RSST Using a Cut-Off Value of 5

\begin{tabular}{|l|l|l|l|}
\hline \multicolumn{2}{|c|}{} & \multicolumn{2}{l|}{ History of Exacerbation in the Past Year } \\
\cline { 3 - 4 } \multicolumn{2}{|c|}{} & Yes & No \\
\hline RSST & $>5$ & 2 & 17 \\
& $\leq 5$ & 25 & 26 \\
\hline
\end{tabular}

Abbreviations: RSST, Repetitive Saliva Swallowing Test.

or less" may therefore be optimal to screen for patients at risk of exacerbation.

The RSST was developed to safely and simply screen patients for functional dysphagia. In their original report, Oguchi et al suggested that when the RSST value is less than 3 times per 30 seconds, further investigation for functional dysphagia should be planned. ${ }^{14}$ Its validity was established through a study of 131 patients with functional dysphagia (with causes of cerebrovascular disorder in 94 patients, brain tumor in 6 , brain injury in 6 , other neurological diseases in 13 , pneumonia in 8 , and other reason in 4). ${ }^{12}$ In that study, an RSST value $<3$ was significantly related to aspiration on videofluorography, and the sensitivity and specificity were 0.98 and 0.66 , respectively. The high sensitivity of the RSST proves its effectiveness as a screening method for dysphagia.

Over the years, several studies have used other cut-off values than those reported initially. For example, in a study of elderly patients with acute pneumonia, RSST $\geq 1$ was regarded as useful for predicting an oral intake at discharge. ${ }^{15}$ In a prospective observational study regarding the switch from intravenous to oral antimicrobials in aspiration pneumonia patients, one of the criteria was RSST $\geq 2 .{ }^{16}$ In an analysis of the feeding function and

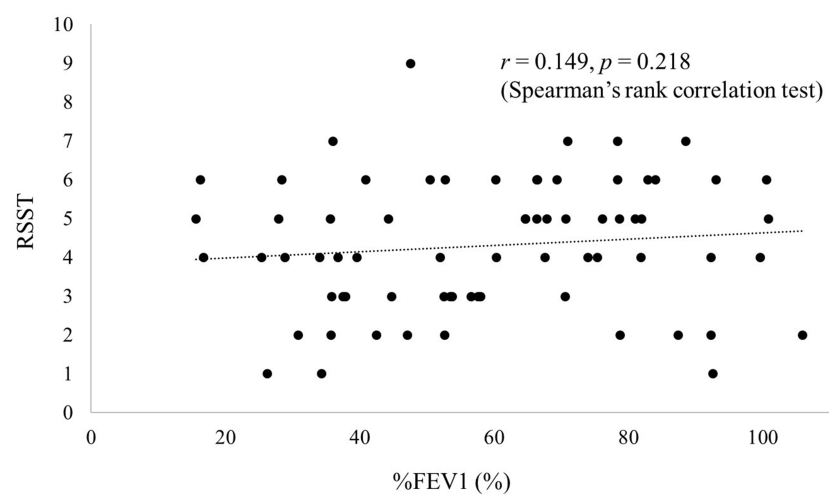

Figure 4 Correlation between the \%FEVI and the number of swallows in the RSST. No significant relationship was detected between the \%FEVI and the number of swallows in the RSST. jaw stability in bedridden elderly patients, an RSST $\leq 3$ was considered abnormal. ${ }^{17}$ However, the optimal cut-off value of the RSST has not been investigated further since its original report.

We hypothesized that the RSST would be a useful tool to screen for dysphagia in patients with COPD if the cutoff level were set higher than that of functional dysphagia. This is because patients with COPD often have subclinical dysphagia, which is challenging to detect with measures validated for cases of more apparent dysphagia, such as patients with acute stroke. As we reported in our previous retrospective study, the results of the RSST were significantly lower in patients with exacerbations in the previous year than in those with no such history. In this prospective study, we were able to show that patients with a low RSST value were at a significantly increased risk of exacerbation in the next year. In addition, the optimal cutoff value of the RSST in this situation was found to be 5 .

Our results differed from those of previous reports, which state that the SSPT results are correlated with the history of COPD exacerbation. ${ }^{3,4}$ We suspect that dysphagia in patients with COPD is more pronounced in repetitive efforts, as evaluated with the RSST, than with a one-timeonly reflection test, such as the SSPT, due to the characteristic changes in the coordination of deglutition and respiration. ${ }^{18}$ The altered respiratory pattern due to COPD reportedly contributes to the increase in the incidence of inspiration occurring immediately before or after swallowing, as opposed to the more common pattern, in which expiration occurs before and after swallowing in healthy individuals. The lack of coordination between respiration and swallowing is said to put patients with COPD at risk of aspiration. $^{18}$ This unique pathophysiology of dysphagia may be the reason why dysphagia in COPD patients is more pronounced with repetitive effort, such as with the RSST, which requires frequent breath-holding, than with a one-time-only reflection test, such as the SSPT. Interestingly, Ohta et al reported that the RSST may be more sensitive for detecting dysphagia in mild COPD patients than SSPT. ${ }^{19}$ However, they did not describe the relationship between the RSST results and COPD exacerbation.

Patients with COPD have many factors that cause dysphagia, ${ }^{2}$ including patient background factors, such as a smoking history and older age; respiratory issues, such as altered respiratory patterns and a lack of respirationswallowing coordination; and systemic complications of COPD, such as GERD, sarcopenia, frailty, and sleep apnea 
syndrome. These multifactorial causes of dysphagia make dysphagia due to COPD unique. Therefore, when screening for dysphagia in patients with COPD, a method that is capable of screening for multiple aspects of the swallowing function is necessary. We suspect that this is why screening tests such as the EAT-10, SSPT, and WST, which concentrate on a specific aspect of swallowing, are not aprticualrly useful in this population. The RSST, which requires sufficient respiration-swallowing coordination to enable repeated swallowing, adequate musculature, cognition, and general well-being, is an effective method of screening for the swallowing function as a whole.

The ECLIPSE study found that there are phenotypes prone to exacerbation, regardless of COPD severity. ${ }^{1}$ The presence of COPD exacerbation in the previous year is known to be the strongest predictor of exacerbation in the following year. ${ }^{1}$ This tendency was also found to be true in the present study; however, it was not the strongest predictor. This may be because many exacerbations are unreported, unrealized, or unrecorded, especially among Japanese COPD patients. $^{20}$ Relying solely on a history of exacerbation does not allow for an accurate assessment. An objective predictor is necessary in order to assess the risk of exacerbation effectively. The present findings indicate that RSST can be a valid objective predictor for those at risk of future exacerbation. It was also a stronger predictor than the presence of exacerbation in the previous year. The feasibility of the RSST also makes it an excellent screening tool for all settings, including outpatient clinics, primary care settings, and even home care or nursing facilities.

McKinstry et al demonstrated the ability to improve dysphagia in patients with COPD through patient education and adequate rehabilitation. ${ }^{21}$ However, whether or not a particular training improves the risk of COPD exacerbation and the prognosis in COPD patients remains unclear. Oral care is also an essential intervention for patients at risk of dysphagia. Dysphagia screening may be a key method for identifying the phenotype at risk for exacerbation, which is also modifiable.

Several limitations associated with the present study warrant mention. First, this study was a relatively small, single-center cohort. Second, the history of exacerbation was obtained through medical records and patient recollection. Only moderate to severe exacerbation was counted as past exacerbation in order to minimize the effect of a spotty memory. There is a qualitative aspect to the assessment of vocal change in the WST, so its results might have differed according to the physician performing the test. However, all physicians underwent a practice protocol to standardize their judgments, and test results were judged by multiple physicians whenever possible. Finally, the time-to-event analysis was carried out in a univariate analysis. Future studies with multivariate analyses and including all past exacerbations are awaited.

To our knowledge, this is the first study to investigate the optimal cut-off value of the RSST in patients with COPD in relation to the risk of future exacerbation. Further efforts to determine ideal intervention for those at risk are awaited.

\section{Conclusion}

An RSST cut-off value of 5 may be a strong predictor of COPD exacerbation.

\section{Acknowledgments}

The authors would like to express their utmost gratitude to Professor Yoshitaka Oku (Hyogo Medical College) for his guidance throuought the study. Gratitude also goes out to the following members of the Iizuka Hospital Department of Respiratory Medicine for their contribution to this study: Masanobu Okahisa, Yuki Goto, Kojin Murakami, and Noriyuki Ebi.

\section{Disclosure}

The authors report no conflicts of interest in this work.

\section{References}

1. Hurst JR, Vestbo J, Anzueto A, et al. Susceptibility to exacerbation in chronic obstructive pulmonary disease. $N$ Engl J Med. 2010; 363:1128-1137. doi:10.1056/NEJMoa0909883

2. Steidl E, Ribeiro CS, Gonçalves BF, Fernandes N, Antunes V, Mancopes R. Relationship between dysphagia and exacerbations in chronic obstructive pulmonary disease: a literature review. Int Arch Otorhinolaryngol. 2015;19:74-79. doi:10.1055/s-0034-1376430

3. Terada K, Muro S, Ohara T, et al. Abnormal swallowing reflex and COPD exacerbations. Chest. 2010;137:326-332. doi:10.1378/chest.090482

4. Kobayashi S, Kubo H, Yanai M. Impairment of the swallowing reflex in exacerbations of COPD. Thorax. 2007;62:1017. doi:10.1136/thx.20 07.084715

5. Yoshimatsu Y, Tobino K, Sueyasu T, et al. Repetitive saliva swallowing test and water swallowing test may identify a COPD phenotype at high risk of exacerbation. Clin Respir J. 2019;13:321-327. doi:10.11 11/crj.2019.13.issue-5

6. Vogelmeier CF, Criner GJ, Martinez FJ, et al. Global strategy for the diagnosis, management, and prevention of chronic obstructive lung disease 2017 report. GOLD executive summary. Am J Respir Crit Care Med. 2017;195:557. doi:10.1164/rccm.201701-0218PP

7. Kim V, Aaron SD. What is a COPD exacerbation? Current definitions, pitfalls, challenges and opportunities for improvement. Eur Respir J. 2018;52:1801261. doi:10.1183/13993003.01261-2018 
8. Anthonisen NR, Manfreda J, Warren CP, Hershfield ES, Harding GK, Nelson NA. Antibiotic therapy in exacerbations of chronic obstructive pulmonary disease. Ann Intern Med. 1987;106:196-204. doi:10. 7326/0003-4819-106-2-196

9. Belafsky PC, Mouadeb DA, Rees CJ, et al. Validity and reliability of the Eating Assessment Tool (EAT-10). Ann Otol Rhinol Laryngol. 2008;117(12):919-924. doi:10.1177/000348940811701210

10. Hidetaka W, Jun K. Translation, reliability, and validity of the Japanese version of the 10-item Eating Assessment Tool (EAT-10) for the screening of dysphagia. JJSPEN. 2014;29:871-876.

11. Kusano M, Shimoyama Y, Sugimoto S, et al. Development and evaluation of FSSG: frequency scale for the symptoms of GERD. J Gastroenterol. 2004;39:888-891. doi:10.1007/s00535-004-1417-7

12. Oguchi K, Saitoh E, Baba M, Kusudo M, Tanaka T, Onogi K. The repetitive saliva swallowing test (RSST) as a screening test of functional dysphagia (2). Validity of RSST. Jpn J Rehabil Med. 2000;38:383-388. doi:10.2490/jjrm1963.37.383

13. Kubota T, Mishima H, Hanada M, Namba I, Kojima Y. Dysphagia paralytica in cerebrovascular disease: screening test and its clinical application. Sogo Rihabiriteshon. 1982;10:271-276.

14. Oguchi K, Saitoh E, Mizuno M, Baba M, Okui M, Suzuki M. The repetitive saliva swallowing test (RSST) as a screening test of functional dysphagia (1). Normal values of RSST. Jpn J Rehabil Med. 2000;37:375-382. doi:10.2490/jjrm1963.37.375
15. Oba S, Tohara H, Nakane A, Tomita M, Minakuchi S, Uematsu H Screening tests for predicting the prognosis of oral intake in elderly patients with acute pneumonia. Odontology. 2017;105(1):96-102. doi:10.1007/s10266-016-0238-5

16. Uni M, Nishimura N, Yamano Y, et al. Efficacy of early switch from intravenous to oral animicrobials in patients with aspiration pneumonia: a prospective observational study. Respir Investig. 2015;53 (5):225-231. doi:10.1016/j.resinv.2015.04.004

17. Tamura F, Mizukami M, Ayano R, Mukai Y. Analysis of feeding function and jaw stability in bedridden elderly. Dysphagia. 2002;17 (3):235-241. doi:10.1007/s00455-002-0063-6

18. Nagami S, Oku Y, Yagi N, et al. Breathing-swallowing discoordination is associated with frequent exacerbations of COPD. BMJ Open Resp Res. 2017;4:e00202. doi:10.1136/bmjresp-2017-000202

19. Ohta K, Murata K, Takahashi T, Minatani S, Sako S, Kanada Y. Evaluation of swallowing function by two screening tests in primary COPD. Eur Respir J. 2009;34:280-281. doi:10.1183/09031936.000 16909

20. Ishii $T$, Nishimura $M$, Akimoto A, James $M H$, Jones $P$. Understanding low COPD exacerbation rates in Japan: a review and comparison with other countries. Int J Chron Obstruct Pulmon Dis. 2018;13:3459-3471. doi:10.2147/COPD

21. McKinstry A, Tranter M, Sweeney J. Outcomes of dysphagia intervention in a pulmonary rehabilitation program. Dysphagia. 2010; Jun;25:104-111. doi:10.1007/s00455-009-9230-3

\section{Publish your work in this journal}

The International Journal of COPD is an international, peer-reviewed journal of therapeutics and pharmacology focusing on concise rapid reporting of clinical studies and reviews in COPD. Special focus is given to the pathophysiological processes underlying the disease, intervention programs, patient focused education, and self management protocols. This journal is indexed on PubMed Central, MedLine and CAS. The manuscript management system is completely online and includes a very quick and fair peer-review system, which is all easy to use. Visit http://www.dovepress.com/testimonials.php to read real quotes from published authors. 